\title{
ARTICLE \\ The missing piece in E. Cassirer's theory of symbolic forms: the economy
}

\author{
Georg D. Blind ${ }^{1}$ D $\cdot$ Raji Steineck ${ }^{1}$
}

Received: 29 June 2020 / Accepted: 30 September 2020 / Published online: 23 October 2020

(c) The Author(s) 2020

\begin{abstract}
Ernst Cassirer's Philosophy of Symbolic Forms (PSF) primarily reflects on culture as a system of normative domains that are path-dependently configured. PSF elaborates on the domains of myth/religion, language, and science, but misses a discussion of the economy. By sketching a corresponding exposition, we contribute to the ongoing discussion of how economic science may investigate the world beyond utility functions. Our argument proceeds along historical and comparative lines with a 'reciprocal comparison' of the medieval economies of Europe and Japan. We thus approach the normative essence of economic thought and behaviour and test its variability in socio-cultural contexts diverging from 'now' and 'here'. Our sketch of the economy as a symbolic form has important implications for the theoretical understanding of change in social systems. We argue that existing factors of change recognised in the economics discipline, such as fluctuations in supply and demand, and institutional innovation, critically require a superposition with patterns of cognition as they guide agents in their grasp of economic problems and, consequently, in their responses that shape material economies. We suggest that conceiving of the economy as a symbolic form makes these patterns of cognition accessible.
\end{abstract}

Keywords Philosophy of symbolic forms · Cassirer · Theory of economic evolution · Time in economic reasoning · History of economic thought

JEL Classification A12 [Relation of Economics to Other Disciplines] - B11 [History of Econ Though: Preclassical (Ancient Medieval Mercantilist Physiocratic)] · B52 [Current heterodox approaches: Historical $\bullet$ Institutional $\bullet$ Evolutionary]

Georg D. Blind

georg.blind@uzh.ch

1 University of Zurich, Zurich, Switzerland 


\section{Introduction}

Ernst Cassirer, a disciple of the neo-Kantian school, is a heavyweight in philosophical discourse. With well over 50,000 citations, his works have been cited more often than those of famous economists such as Jan Tinbergen, Reinhard Selten, and Vernon Smith (1969, 1994, and 2002 Nobel Laureates). While the economics literature continues to show some traces of its origins in moral philosophy with a small but steady stream of references to philosophers, Cassirer's work is almost entirely absent from it.

Cassirer's magnum opus, his three-volume Philosophy of Symbolic Forms (1923-1929; henceforth PSF), regroups what may be regarded as a cultural philosophy of language, mythical thought, and science. While the absence of a corresponding treatise on 'the economy as a symbolic form' may explain the lack of references to $P S F$ in the economics literature, it does not imply that his work is irrelevant for the discipline of economics. On the contrary, Klattenhoff's recent suggestion that we should understand money as a symbol with important functions in Cassirer's sense (Klattenhoff 2016, 2018) and Miklautz's analysis of the sphere of commodities as a symbolic form (Miklautz 2005) illustrate the potential contribution of PSF to economic thought.

With the growing recognition of economics as a cultural science (Throsby 2001; Dopfer 2011) and as a cultural "artefact" itself (Hartman 1977), a critical appraisal of PSF's potential bearing on economics seems a very timely endeavour. Notably, the economics discipline has recently witnessed a strong surge in discussions around the insufficient recognition of how economic rationality and behaviour depend on cultural conditions. Adding to such variety 'in space' (i.e., between individual actors), a second stream of criticism toward received economic theory refers to its lack of reflection on change as 'variety in time'. Mueller (2004) offers a concise overview of these two discussions.

While an "ultimate reduction of all cultural forms to the one form of logic seems to be implied by the concept of philosophy itself" (Cassirer 1923-1929[1953-1957]: I,84), ${ }^{1}$ Cassirer eschews any reductionist reading of that principle. On the contrary, he sets out to build a theory of culture as a system of mutually irreducible, complementary domains of meaning (starting with language, myth, and science in the three volumes of his magnum opus). As evident from his writings on technology or law, and his last systematic exposition, the Essay on Man, Cassirer came to think of culture as an open, evolving system of such domains. We want to argue in this paper that economy is fully deserving of a place in this system. ${ }^{2}$

\footnotetext{
1 The German original reads: "Und in der Tat scheint diese letzte Zentrierung aller geistigen Formen in dereinen logischen Form durch den Begriff der Philosophie selbst [...] notwendig gefordert zu sein." English translation as of 1953 Yale University press edition.

${ }^{2}$ In his earlier attempts at systematization, Cassirer assumes a link in the evolution of symbolic forms from myth, dominated by the symbolic function of expression, through language, moving to the higher level of representation, and finally, to science, which makes full use of the highest function of "pure meaning", that is, meaning purely constituted by internal semantic relations (Cassirer 1923-29: II). This would mean that the system of symbolic forms would be completed with the emergence of modern science. However, in his later works on technology, law, and art, he opens up the idea of symbolic forms
} 
Cassirer's theory builds on the key observation that the human grasp of reality is fundamentally mediated through symbols. This implies a mutual existential dependency of the universal and the particular (Cassirer 1923-1929[1953-1957]: I, 86). ${ }^{3} \mathrm{~A}$ symbol in the strict sense is a material entity that is produced to "stand in" for something else (like a red traffic light for the order "stop and wait"). It is dependent on the material conditions of production (no traffic lights without electricity and individual motorized transport), and on socially shared rules of articulation and application (colour coding, traffic regulations). While the said rules allow one symbol to stand in for a manifold of objects, or thoughts, or modes of behaviour, they are bound to a specific normative domain. In the words of Luft, they belong to distinct "cultural spaces of meaning" (Luft 2004). And they develop and change over time, not least due to changes in technology and other socio-cultural conditions.

The context dependence of symbolic representation implies a twofold differentiation, in normative domains, and in path-dependently evolved configurations (Steineck 2014: 5, Steineck 2020). In other words, while each instantiation of a normative domain/symbolic form represents a fundamental normative orientation, its actual formation is shaped by the particular social and historical context. Accordingly, it has to negotiate general rules of society that define the "opportunity space" of "permissible operations" (Dopfer and Potts 2008: 9) for each domain. ${ }^{4}$ At the same time, each symbolic articulation (scientific paper, work of art, and religious ritual) has to operate with a transmitted repertoire and the available sign systems to be understandable. This implies that innovation is possible, but only within specific boundaries. $^{5}$

\section{Footnote 2 (continued)}

to the realm of the practical and the aesthetic (Cassirer 1985; 2005; 2004; 1979: 145-215). In his Essay on Man, he suggests that the symbolic forms are irreducible and complementary to each other (Cassirer 1992: 181, 244). At the same time, he retains the evolutionary scheme as a paradigm of development for each symbolic form: each form develops from a mythical state, where it is dominated by the function of expression, through one dominated by representation before finally developing its own semantics of "pure meaning". As one of us has argued theoretically and demonstrated for the symbolic form of myth, this evolutionary paradigm is deeply problematic (Steineck 2014: 59-67, 130-35; 2017); we therefore retain only the idea of the complementarity of symbolic forms.

3 This also resolves the problem of the distinction between intelligible and sensible worlds encountered in idealism (Cassirer 1923: I,21).

4 Such space may be markedly different, for example, for art in a state defining itself by religion, such as seventeenth-century Zurich or present-day Iran, as opposed to secular republics such as classical Athens or contemporary Japan.

5 E.g., the development of mathematics in ancient Rome being hampered by the limitations of the available sign system. Cassirer understands the historical development of each symbolic form as an evolution starting with initial formations dominated by expressive/mimetic symbolisation, which has no clear distinction between the sign and its referent. The next stage is governed by representative symbols and analogisms, with symbols standing in for experiential phenomena. Finally, each symbolic form arrives at a stage where its signs are purely defined by their internal relations, which Cassirer equates with "the final, properly symbolic mode of conceptualization" ("die endgültige, die eigentlich-symbolische Form der Begriffsbildung", Cassirer 1923-1929: III 530). This paradigm was developed through Cassirer "s extensive studies in the history of the natural sciences, and it identifies each historical formation with a stage in the development of the symbolic form itself. One of us has proposed a less monolithic view of the history of symbolic forms, which differentiates more clearly between the general symbolic form and its instantiations in various historic formations, and comprises a matrix of formative factors that helps to 
Our application of PSF to the economic sphere takes the form of an initial exploration. A full systematic study, which would have to present a wealth of source materials reflecting the self-understanding of economic agents through global history is obviously beyond the scope of this paper. ${ }^{6}$ In selecting our material, we hold to the general idea of gaining epistemological benefit from a 'reciprocal comparison' (Pomeranz 2000) across time and space, in this case an under-explored geographical and historical juxtaposition that contrasts England to Japan during the latter country's later medieval period (1185 to 1600). This choice of case study also highlights how the "model of economic rationality" found in orthodox economics "does a very poor job of predicting human behaviours" (Quinn 2016) outside a narrowly defined subject matter. As our analysis will show both the internal historic formation of the economic sphere, and its entanglement with other symbolic forms-here, most importantly the religious and the economic, are instrumental for understanding variation in configurations of the economy across time and space.

This insight has several implications. First, for economic theorizing, it suggests the need to allow for variation in the reasoning of agents. This is significant, because it downgrades the received assumptions of universal economic rationality to the status of a special case, applying at best to economies dominated by modern capitalist relations of production. For the great many other particular cases, economic theorizing will need to rely on specific forms of rationality. Second, it implies that economic methodology needs to open further toward multidisciplinary approaches. And third, it necessitates more complex empirical enquires for its call to add and integrate the study of reason to that of economic outcomes.

We structure this article as follows. Section 2 introduces the core elements of Cassirer's PSF. Section 3 develops a sketch of the economy as a symbolic form. Section 4 compares the medieval economies of Japan and England to illustrate how symbolic representation informs economic outcomes. Section 5 reflects on theoretical implications, methodological consequences, and empirical practice. Section 6 concludes.

\section{The theory of symbolic forms}

The Theory of Symbolic Forms can be described as a "systems theory of cognitive patterns" (Kreis 2010:11), in which patterns are understood as guiding the behaviour of agents including their production of cultural objects. In his work on PSF, a general discontent with the limitations of contemporary epistemology seems to have strongly contributed to Cassirer's motivation. At the time, epistemology was focused almost exclusively on the natural sciences, which-in his view-implied that it

\footnotetext{
Footnote 5 (continued)

operationalize the concept of symbolic form for historical and empirical cultural analysis. See (Raji C. Steineck 2020).

6 This is the method used by Cassirer himself, at least in his studies on the symbolic forms of language and science (vols. 2 and 3 of the $P S F$ ).
} 
could not "provide an adequate methodological basis for the cultural sciences" (Cassirer 1923-1929[1953-1957]: I 69). Cassirer's thought presupposes the accomplishments of critical idealism: "The road does not lead solely from 'data' to 'laws' and from laws back to 'axioms' and 'principles': the axioms and principles themselves, which at a certain stage of knowledge represent the ultimate and most complete solution, must at a later stage become once more a problem." (Cassirer 1923[1953]: I 74). Clearly, this notion foreshadows the problematisation of orthodox economic principles in recent years, by which "the rigid concept of being seems to be thrown into flux" (ibid.). If we accept this evolutionary principle, "the fundamental concepts of each science [...] are regarded no longer as passive images of something given, but as symbols created by the intellect itself' (ibid.:75). Any appreciation of the 'facts', or of 'data', therefore, necessarily needs to take into consideration the theories and perceptions that motivated the quest for them (Cassirer 1992: 56-62, von Glasersfeld 1989).

Importantly, Cassirer holds that a "concept of culture cannot be detached from the fundamental forms and directions of human activity: here 'being' can be apprehended only in 'action."' (Cassirer 1923[1953]: I 80). PSF thus proposes that all existence has both physical and cognitive properties (Kreis 2010: 16). Symbols in Cassirer's understanding result from the total of all meaningful operations (ibid.). Where operations are not random, but build on rules (condition-action statements), their execution enables a function to be served, rendering the corresponding operations meaningful.

As the attribution of meaning requires an act of an individual agent, conceiving the arts, religion, the sciences, and significantly, the economy in terms of a symbolic form retains a key element of methodological individualism. However, individuals perceive, experience, and understand the world, and themselves, by way of engagement with symbolic forms - Luft's "cultural spaces of meaning"-and these are, in essence, socially constituted. What is considered valid, be it aesthetically, technologically, or economically, is thus conceived to be so not only for the individual, but for the entire population of agents sharing the relevant symbolic form. Therefore, "methodological individualism" in Cassirer's PSF does not imply "social atomism"? 7

Finally, as a concretisation of Kant's Critique of Pure Reason, PSF embraces what contemporary scholarship would call 'historicity' ${ }^{8}$ and-as a corollary-'localism' (see, e.g., Katzner 2002; Blind 2017:163). This is manifest in Cassirer's recognition that language, and indeed, all symbolic cultural systems, are dependent on space and time (Kreis 2010: 26) — and that, therefore, the "form" that is the object proper of philosophical analysis "can be found only through immersion in the empirical material, but this is accessible to us [...] only in a historical form" (Cassirer et al. 1998:

\footnotetext{
7 See Cassirer's discussion of "Basis Phenomena", in (Cassirer 1998: 136-43, 153-66).

8 'Historicity' here refers to the position that all instantiations of symbolic forms comprise pathdependently developed sign systems, media formats, social institutions, and knowledge repertoires, and are therefore historically specific. Conversely, no single instantiation represents the 'pure' or 'universal' symbolic form.
} 
165). Building on this fundamental insight, we can say that we never encounter a symbolic form 'as such', but only one of its historically and locally specific formations. ${ }^{9}$ Our later sketch, thus, may be labelled 'history-friendly'.

Central to maintaining our later argument (Sect. 3) in line with Cassirer's spirit is the distinction of worldviews and their many particular functions, namely to deliver "purposeful outcomes" as in von Bertalanffy's understanding (Bertalanffy 1950: 159). This stems from the very basis of PSF: no object allows for direct appreciation, but critically depends on the relevant "formal context" (Cassirer 1923-1929[1953-57]: I 95). That context, in turn, is provided by the symbolic representation that channels all cognitive access (Steineck 2014: 24). This dichotomy equally applies to the distinction between economic reasoning (based on particular worldviews), and economic outcomes (originating from agents assuming functions).

The link between operations and their cognitive foundations is function. As all thought implies a function (Kreis 2010: 60), and as thought becomes manifest through language, all terms are associated with a function. A function, in turn, denotes the unifying aspect in recurring actions, and may thus be coded as a condition-action statement. In Cassirer, functions constitute a relational association between entities - both physical and cognitive (Cassirer 1990: 410-11). The timeand space-dependent totality of symbol systems are used for:

(i) The expression of functions and the operations required to execute them,

(ii) Of objects created thereby,

(iii) The social relations between agents involved.

This constitutes what we propose to call the 'symbolic configuration'. As such it specifies the particular historic formations of a symbolic form.

This brings us directly to the thorny issue of delineating what it is precisely that defines the artefacts, rules, ideas, lifeworlds, and social spheres pertaining to a specific symbolic form. Cassirer has shed away from giving an outright definition of his key term, but Kreis (2010: 449) has provided a list of four defining elements of a symbolic form:

1 A general normative concept embracing the ensemble of rules informing the formation of domain-specific objects.

2 A lifeworld resulting from the exchange of particular expressions.

3 A general concept representing the totality of ideas that can be expressed in terms of (1).

4 A general concept representing specific social spheres of action, namely

5 The set of social groups following the rules of (1),

6 The set of social practices linked to the conduct of (1).

\footnotetext{
9 Methodologically, as a slow-moving variable, a historical/local formation may be interpolated from the encounter with numerous interrelated instantiations. For instance, in the case of science, laboratories, experiments, articles in scientific journals, textbook chapters, course curricula, reports in popular media, and so forth, can serve this purpose.
} 
As a "cultural space of meaning" (Luft 2004), a 'symbolic form' thus stands for the ensemble of rules (1) that guide the behaviour (also 1), imagination, and reasoning (3) of agents into functions. As agents create and exchange artefacts and ideas resulting from this, they build a specific lifeworld (2) with their particular social groups (4a) and practices (4b). Notably, (4a) reflects a theoretical reception of Max Weber's understanding of social groups as being critical in creating and maintaining distinctive intellectual lifeworlds (Bellah 1999: 279).

\section{The economy as a symbolic form}

While even proponents of (early) neo-classical economics such as Carl Menger are known to have admitted that (pecuniary) self-interest is "only one of a number of human motives" (Yagi 1993: 720), a vast majority of research in economics continues to rely on assuming exactly such universal economic rationality, particularly so for empirical works. Assessing economic outcomes based on these grounds might still be sufficiently safe for the study of modern capitalist economies. However, it can lead to flawed conclusions (at worst), or fail to produce useful insights (at best) outside of this 'standard environment'. The case study presented in the subsequent section serves to illustrate why it is necessary to re-consider the rationality underlying economic operations in different socio-economic systems.

Arguably, the assumption of a universal, trans-temporal economic rationality is not a conscious choice for most scholars. It has developed into a given presupposition, implicit not only in most empirical studies, but even so in theoretical works. For instance, if we take Robbins' classic definition of economics as the study of "human behaviour as a relationship between ends and scarce means which have alternative uses" (Robbins 1932: 15), there is no direct mention of the assumption. While Robbins defies the notion of economists assuming the sole pursuit of (pecuniary) self-interest as a "foolish and exasperating accusation "(1932: 97), he still admits that the assumption is "convenient" (ibid p. 98).

We hold that the analysis of most configurations of the economic realm requires to abandon exactly this convenience. With Klattenhoff (2018), we believe that economic analysis needs to embrace the cognitive foundation that turns behaviour into functional operations, as well as the cultural objects (physical and intangible alike) created and sustained through such operations (e.g., goods, markets, and businesses). This promises to enlarge epistemological potential, particularly when researching economies not governed by modern capitalist relations of production.

Partially coinciding with criticism from outside the discipline (e.g., Gudeman 1986), economics is increasingly recognised as a cultural science (Stanfield 1995; Throsby 2001; Dopfer 2011). However, the theoretical basis for this reasoning remains fragmentary. Here, the $P S F$ may help to fill that particular gap. In Cassirer's own words, PSF provides a "morphology of the human spirit", which is required "to arrive at a clearer and more reliable methodological approach to the individual cultural sciences" (1923-1929[1953-1957]: I 69).

We further posit that the domain of the economic fulfills all the definitional criteria of a symbolic form listed in Sect. 2 and should be seen as an important part of 
the morphology of human culture. Conversely, taking full account of these criteria will provide a more comprehensive understanding of the scope of economic problems and phenomena. Pertaining to element 1 ("a general concept representing the rules and operations leading to the formation of domain-specific objects"), we hold that the economy may be defined as the purpose of provisioning goods and preventing economic harm (see discussion below); this purpose informs the ensemble of economic rules and the ensuing totality of economic operations, including acts of cognition. ${ }^{10}$ Equally, we see 2 (a "lifeworld") and 3 (a "sphere of ideas") as satisfied, because the economy not only represents a domain of interaction frequently contrasted to others (such as religion or art), but also implies a specific worldview, and a space of domain-specific imagination (from entrepreneurial ideas to social welfare policies). Importantly, 4a ("the set of social groups following the rules of 1") is not explicitly recognised in much of received contemporary economic thought. The importance of this element, however, has been prominently stressed in more recent work exploring sub-populations of agents as 'carriers' of rules both empirically (e.g., Ostrom 1990; Ostrom and Basurto 2011), and theoretically (e.g., Dopfer and Potts 2008). In turn, 4b ("the set of social practices linked to the conduct of 1") conforms strongly to received notions, with production, exchange, and consumption (compare Veblen 1899) as the most pertinent practices.

Unlike our defining of the economy as a symbolic form, Robbins' received formula obviously attempts to define the science of economics, and not the sphere of the economy as such. One might infer that, to Robbins and those that have followed him, the defining characteristic of the economic sphere is the "relationship between ends and scarce means which have alternative uses". In our view, this is helpful in locating the economic in the sphere of the practical (the 'moral sciences', as older tradition had it). However, from the perspective of the PSF, Robbins' definition leads to a view of the economy that includes too much on one hand, and not enough on the other.

First, it seems overly broad to define all behaviour pertaining to ends and scarce means with alternative uses as economic, if one accounts with PSF for the plurality of co-existing symbolic forms. For instance, wine and other forms of fermented drinks may be used in religious rituals to drink, to sprinkle, or to be left to evaporate (to be drunk by the gods, so to speak). It is scarce (probably), and it has alternative uses (surely). However, the choice of ritual and concomitant behaviour is not an economic one; it is a religious one. To broaden the field of economics to all relationships between ends and scarce means which have alternative uses is to lose sight of what is specifically economic. ${ }^{11}$

\footnotetext{
10 This builds directly on Cassirer's understanding whereby "every 'reproduction' of a content embodies a new level of "reflection.'” (Cassirer 1923-1929[1953-1957]: I 90).

11 To give another example: Did Beethoven make an economic choice when he decided to repeat part of the main theme in the coda to the first movement of his 'Pastoral' sonata? Paper was scarce and had alternative uses; the listener's attention is equally scarce and has alternative uses. Still, one may argue that the decision is primarily a consequence of a compositional choice earlier in the movement, designed to maintain the overall balance: it is an aesthetic choice, not an economic one.
} 
Second, the link to scarcity is culturally and historically specific; it has been characterised as "peculiarly appropriate to [modern] market economies" (Gowdy and Sahlins 1998: 6). It seems appropriate, therefore, neither to contemporary economies of abundance, nor to economies moderated by the presence of other symbolic forms. For instance, superposition with the religious may motivate the use of 'sufficiency' over 'efficiency' in an economy where eventual surpluses are meant to remain for the gods, or the dead (compare the evidence on offerings following surplus conditions in the neolithic revolution in Fuller and Grandjean 2001).

Taking recourse to pre-marginalist theory may direct us towards a broader, but still sufficiently specific concept of the economy. In terms of the above definition of symbolic forms, we can appreciate that earlier theories are centred on the lifeworld' dimension of the economy (and less, as in much of current economics, on the 'behavioural' dimension). For instance, in Say, we find the notion that 'l'économie politique [...] montre comment se forment, se distribuent et se consomment les richesses qui satisfont aux besoins des sociétés" (Say 1803: I; emphasis added). Similarly, Adam Smith defined the central economic objective as providing "a plentiful revenue or subsistence" (Smith 1776: 428). Both views echo the central idea of the Pseudo-Aristotelian Oeconomia, namely that economics is about providing or possessing "the means to a happy life" (book 1.1, cf. Aristotle and Forster 1920). The Oeconomia also identifies four fundamental economic abilities: the acquisition, preservation, management, and proper use of wealth (ibid., book 1.6). Looking beyond Europe, we find that the Indian political treatise Arthashastra (second to third century $\mathrm{CE}$ ) gives a metonymical definition of the economy (skt. varta) by way of "agriculture, animal husbandry, and commerce" (Kautilya and Meyer 1977: 4). Its subsequent material discussion of various spheres of production (basic and luxury goods alike) as well as logistics (roads and ships) (Kautilya and Meyer 1977: 116-225) clearly hints at ways to arrive at greater societal well-being.

Synthesising these ideas spanning several epochs and continents, we can now further elaborate on our earlier definition of the function of an economy as "the provision of goods and, conversely, the prevention of economic harm". A 'good' here means a transitive thing (a material object, a symbol, an action, a quality, which may be collectively perceived, and which can be acquired and transferred between agents) that may serve as a means to sustain and further human life and well-being. Not everything that is conducive to human well-being is therefore a 'good' in this particular, economic sense; friendship, for example, is not transferable, and therefore not an economic good. 'Economic harm' is here understood as an object that is detrimental to human life and well-being; likewise, not everything that is detrimental to human life implies damage in this economic sense: the loss of a loved one, for example, is usually perceived as harmful, but it may or may not imply economic damage. 'Provision' in the economic sense means to have something at one's disposal. As Amartya Sen has famously argued, it is not sufficient that a good (such as food) is generally available, but one has to have access to it. Only where a good is physically accessible, and those who need it are also entitled to use it, can it serve its economic function of sustaining human life (Sen 1981).

What we have gained from these brief reflections is, therefore, first, a necessary specification-an economic system is to provide goods and to prevent economic 
harm. Mirrored against the definition of a symbolic form given in Sect. 2, this implies that the symbolic form of the economy provides the ensemble of rules (definition element 1) that enable functions to deliver the purposes of provisioning goods and preventing economic harm. As agents conduct corresponding operations in exchange with each other, they co-create their proper economic lifeworld (element 2 ) and ways of reasoning (element 3). A specific social process-structure emerges, in which social practices (element $4 \mathrm{a}$ ) contribute the process part to the structural elements given by social groups (element $4 \mathrm{~b}$ ).

Second, we can rest assured that broadening the subject matter of economics by defining it as a symbolic form will facilitate the synthesising of the received wisdom of various regions and ages. In conceptualising the economy as a symbolic form, we are neither bound to exclusively focus on the riches that satisfy the needs of societies, nor on behaviour related to scarce means with alternative uses. Instead, we can include both, and more, for example the study of economic rules, theories, or social institutions and their interactions with each other and with the former. Furthermore, we can understand that economics cannot rely on a universal theory of human behaviour, or society, or culture, but is domain-specific, which makes the relation between the economic realm and other cultural domains a necessary, and legitimate, field of inquiry and reflection.

Comparing configurations of the economy as they differ in space and time is the promise offered by applying $P S F$ to the economic sphere. At the same time, and crucially, a classification system may help to enable this bold endeavour. Cassirer's own work is not much help in this regard, as he did not analyse the economy as a symbolic form, and, in spite of his general ideas on the historicity of symbolic forms, neither did he develop a terminology nor a methodology for analysing historic formations of symbolic forms. To come up with a tentative analytical system, a reflection on the systemic aspects of 'provision with goods' may serve to identify the basic vectors for building a matrix of variants. ${ }^{12}$

In order for goods to serve as provisions for someone, they need to exist; the first vector is therefore that of production (in the broad sense of bringing a good into existence). Second, goods have to be available for use; that is, they need to be present at the temporal-spatial location where they can fulfill their function of furthering the life of an individual or a collective: this corresponds to the vector of physical appropriation. Third, they need to be 'socially available'; that is, their association with an individual or collective needs to be socially valid: the vector of social recognition, entitlement, or ownership rights; and in a wider sense, the vector of economic social relations. A fourth dimension is 'economic means'-operations, objects, and institutions specifically designed for the sake of the economic sphere, to facilitate the provision, circulation, and socially accepted acquisition or transfer of goods: the vector of economic media, such as money, deeds, or patents.

A first rough typology of 'economies' (configurations of the symbolic form of the economy) may then be built by characterising them through the relative

\footnotetext{
12 The following systematisation is inspired by Johannes Heinrich's "periodic table of actions" (Heinrichs 2007), but is not confined to it.
} 
weight of these one vectors (which does not mean that the others are excluded, but simply that they play a minor part): subsistence economies, for example, are dominated by production. The economies of hunter and gatherer societies, or those of predatory collectives such as pirates, are built on appropriation. Family, clan, or feudal economies are dominated by the vector of social entitlements, and formerly planned economies may equally see the substantial weight in this vector (Ledeneva 1998; Butler and Purchase 2004). Most market economies are dominated by the vector of economic media, but arguably to varying degrees. Depending on the dominant vector, particular economic phenomena may or may not arise. For instance, the distribution of goods (in terms of logistics) may be observed in economies dominated by the second, third, and fourth vectors (transport of 'loot' in the second, in-kind tithes in the third, and merchandise in the fourth). The exchange of goods for money, i.e., trade, including multi-stage variants, is necessarily only to be observed in sufficiently monetised economies. Production and appropriation economies have relatively little need for specific symbolic interaction; in contrast, economies dominated by entitlements or media require elaborate communication, and will exhibit a more differentiated configuration of economic symbols, concepts and institutions/agent groups (compare definitional criteria 2, 3, 4; in Sect. 2).

Evidently, 'economic rationality' can be very different in each of these archetypical configurations. Even more so, we expect to find substantial variations in 'economic reasoning' in empirical configurations as they not only depend on the weighting of these vectors, but also on time- and space-dependent inter-relationships with other symbolic forms. Put simply, economic agents will behave differently depending on the type of economy they are operating in. From this, we also understand that received homo oeconomicus represents but an abstraction of a time- and spacespecific configuration of economic reasoning. Reflecting on our earlier definition of a symbolic form as (1) comprising the ensemble of rules guiding the behaviour and reasoning of agents, and (2) the following of rules as enabling operations to effect economically meaningful functions, we hold that this may lead us to a terminology liberated from the limitations imposed on the received understanding of economic rationality.

\section{How conceiving the economy as a symbolic form helps to make sense of differing outcomes in economic configurations: a comparative case study}

In presenting our case study, we start by broadly following a received approach that relies on a resource-based analytical view of economic outcomes as observed for our objects of study, the medieval economies of England and Japan. This is to showcase how the resource-based approach-mere representation in Cassirer's functional hierarchy-falls short of producing meaningful explanation for the difference in outcomes observed for this pair of temporally and spatially distant economic formations. As we shall see, however, widening the perspective to systematically include the particular characteristics of the corresponding configurations of the economy as a symbolic form opens new routes to describing and 
explaining commonalities and differences between them. From the perspective of the PSF, this implies an attempt to reconstruct from historical sources and data the meaning, that is, the patterns of cognition that were guiding the behaviour of agents in these economies.

In terms of economic activity and output, the medieval societies of England and Japan were both strongly dominated by agricultural production. While neither was a subsistence economy, surplus available to extraction remained not only at low levels, but necessitated precautions against recurring years of negative primary surplus. For Japan, Totman calculates average surplus (i.e., share of the secondary and tertiary sectors) as around 7\% for the Nara period (eighth century CE), but argues that new seeds and agricultural technologies boosted this figure from the tenth and eleventh centuries onwards, leading to substantial population growth and the development of artisan manufacture and trade (Totman 2000). Still, there was a major famine every 7.4 years between 1280 and 1450, and every 5.4 years between 1450 and 1600 (Farris 2006: 174), implying that near-subsistence conditions remained a reality for a major share of the populace.

The situation was similar in England. McCloskey and Nash (1984) report that in the late medieval period hardly any storage of grain took place, and that almost every harvest was preceded by famine. More recent scholarship, however, tends to question these claims, providing proof of substantial stockpiling which effectively evened out grain supply over the course of the year (Clark 2015). Even more disruptive than famine were the recurring pandemic episodes that struck Europe from the late thirteenth century. For instance, on the British Isles, plague led to a population decline of more than 55\% between 1270 and 1450 (Broadberry et al. 2015: 179). While it implied a temporal increase in per-capita GDP, the relatively higher death toll in urban settlements disadvantaged the secondary and tertiary sectors. Eventually, and with the exception of a few regions such as the Netherlands and parts of Italy from the late fourteenth century, "it was only after 1870 that labor income rose decisively above medieval levels" in Europe (Allen 2001: 445).

Abstracting from differences in climate, both medieval economies alike were thus generally struggling with challenges brought about by nature, including systemic phenomena (seasonality), and idiosyncratic events (droughts, floods, etc.). Counterstrategies were similar and chiefly included diversification of crops (to counter the former), and stockpiling (to counter the latter). Some recent empirical works allow for a direct comparison of sectoral structures in Japan (Bassino et al. 2015) and England (Broadberry et al. 2011; 2015), because these studies build on a common methodology. Fortunately, the data fully span our investigation period, namely from the thirteenth century to about 1600 . The direct comparison shown in Fig. 1 reveals a substantial difference.

As can be inferred from Fig. 1, the share of the secondary and the tertiary sectors is very different in the two economies. Even if neglecting the 1450 estimate for England-where the shrinking of the secondary and tertiary sectors was due to the Black Death pandemic - the tertiary sector of England's economy was much less important than in Japan and vice versa. Beyond this kind of population-based influences, however, reasoning with the resource-base (with its underlying assumption of uniform economic rationality) does not promise much epistemological gain. 

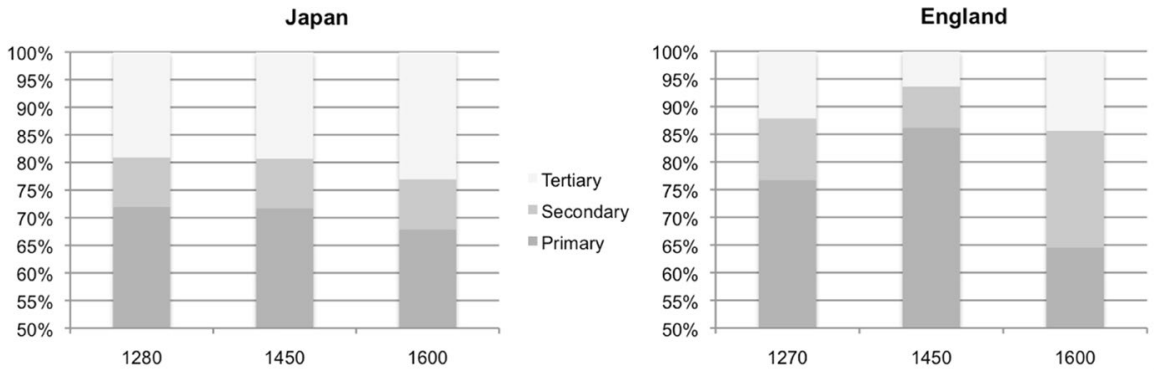

Fig. 1 Sectoral composition of the British and Japanese medieval economies. Calculated from Table 6 in Bassino, Broadberry et al. 2015, p.30 for Japan; Broadberry et al. 2015, p.179-81, and Broadberry Campbell et al. 2011, p.35, Table 9 for England. The estimates of the secondary and tertiary sectors in these studies build on population density and urbanization rates. It may thus still underestimate the weight of the tertiary sector for Japan, where local administrators (Hyakusho) affected important managerial services for the organization of production and trade

Here, we apply the understanding of the economy as a symbolic form. In a first step, we attempt to establish to what extent the four vectors introduced in Sect. 3 have been informing the reasoning of economic agents. The first point to note here is that these medieval economies were not dominated by the vector of production alone, even if near-subsistence conditions were frequently endemic. Neither were these economies dominated by the vector of appropriation. In medieval Europe, economic systems predominantly built on appropriation were limited in scope and/or time; they included Viking pirate collectives (eighth-to-eleventh centuries), or the Victual Brothers during the late fourteenth century. Similarly, while criminal retainers enjoying the patronage of the nobility were reportedly not uncommon (Coyle 2005), they did not become the dominant vector for any sustained period. For Japan, the late Middle Ages are also known as the "Age of Warring States" (1467-1600), which may suggest a sustained dominance by predatory collectives. However, property rights were effectively enforced by nongovernmental institutions, such as Buddhist temples and monasteries, adding a first hint to the more substantial share of the tertiary sector in Japan (Adolphson and Ramseyer 2009).

The dominant vector for much of the medieval period in England, continental Europe, and Japan alike was social entitlement. The economic system in Japan featured feudalistic structures with a vassal/fiefdom organization quite like the manorial system in England. While this comparison has been criticised for a lack of reflection and differentiation (Yasuda 1965: 18), it is safe to argue that there was a strong resemblance between the key functions of the two configurations. Both were initially cash-free systems in which central authorities bestowed fiefdoms on regional rulers, with a multi-level redistribution of land-to-local tenants. In exchange for the right to cultivate these lands, regional rulers organized military units, returned a fraction of crops, and provided corvée labor. Accordingly, a complex system of symbolic exchange developed to establish and maintain the social bonds that were the ultimate basis of entitlements to resources. 
Thus, our comparison finds a considerable resemblance between the two economies in terms of the weight attached to the four vectors. Yet, in a second step, we now look into differences between the rule systems in place for guiding the operations of agents. In doing so, we separately consider the three sectors of our economies under scrutiny at the three points in time given in Fig. 1. One might argue that such analysis simply corresponds to investigating institutional arrangements, but such view would start from structures, and not from the reasoning of agents. As we have argued in Sect. 3, such inferring of the reasoning of agents is crucially required to understand what rules apply to the allocation and enforcement of entitlements (owing to the third vector being dominant), and to configurations relating to expression, imagination, and social agency (Sect. 2, criteria 2, 3, 4).

As a broad but useful generalisation, during the periods governed by the vector of entitlements, the major governing mechanisms in England were explicitly coded in law (e.g., tax matters), whereas in Japan, many of these mechanisms were based on the social/political relations that gave rise to negotiations (e.g., as manifest in the various symbolic exchanges between tenants and local rulers). This created a predominance of legal obligations in England, and of social/political obligations in Japan (Haley 2010). ${ }^{13}$ The difference in practical importance, however, was bound to have a bearing on economic outcomes. In a setting that is based predominantly on personal relations, a relatively larger number of intermediaries involved in the brokering and maintenance of these relations were needed in Japan.

This helps to develop a working hypothesis explaining the relative dominance of the tertiary over the secondary sector during the first part of the period analyzed here. In 1270, the first point in time for which Fig. 1 provides an estimate of the sectoral composition of the economy, remnants of the Chinese-inspired ritsuryo governance system ${ }^{14}$ still required a substantial number of agents to be involved in the management of social entitlements in Japan. In contrast, in England, centuries of albeit meandering - developments following the first unified law code (the ninthcentury Doom Book of Alfred the Great) had contributed to an institutionalisation of the management of entitlements; hence, a lesser share of agents can be assumed to have been involved.

In turn, by 1450 (the second point in time documented in Fig. 1), we see that the vector of economic media (vulgo: money) had come to dominate substantial parts of the economy. By 1600 (the third point of time in Fig. 1), the two systems had been completely transformed into monetised economies. This view stands in contrast to some earlier sources holding that monetisation was not deeply embedded in medieval Japan. Yet, a very different picture emerges from recent scholarship documenting that a majority of transactions were actually settled in cash already by the

\footnotetext{
13 This does not imply that social relations were irrelevant in England-consider, for example, the behavioural rules implicit in the early medieval myth surrounding Beowulf (The prince who in his youth gave presents, to foster relationships that would support his later rule). Nor was the law absent from economic life in Japan, as we can see from the Kamakura Shogunate's attempt to regulate relations between landowners and tenants through the Goseibai shikimoku of 1232.

14 Japanese rulers tried to replicate the Chinese governance system around the turn of the seventh/eighth century, including a criminal code, and - more importantly — an administrative code.
} 
thirteenth century (Segal 2011: 59). This again corresponds to the development in Europe where "money supply expanded dramatically" from the later twelfth century (Naismith 2014: 4).

In contrast to the European experience, however, the introduction of money in the Japanese Middle Ages did not result from minting by domestic authorities, but arose predominantly from the proceeds of exports to China (Sakurai 2008). As the import of coins did not fluctuate strongly, money supply eventually increased just marginally below the combined pace of economic growth and expanding monetisation. The result of this was a mildly deflationary environment with relatively little volatility (Yokoyama 2011; Domoto 2016), forming a stark contrast to inflation-ridden medieval Europe (Hutton 2016). It remains an open research question whether this phenomenon was simply accidental, or whether there was a conscious policy choice in favour of price stability. Either way, even within economies based on social relations/entitlements transitioning to economies dominated by monetary transactions, locally distinct characteristics can be observed in the respective configurations.

While ex-post-observation of differences in agent reasoning is not possible, we can still try to make inference about the impact of these differences on the time-space-dependent formation of the economic domains. In medieval Japan, for example, the authorities were surely not indifferent about monetary affairs. The spread and increasing use of coins gave rise to a number of concerns at the beginning of the Japanese Middle Ages (from 1185), but the government swiftly acknowledged it as a new trend, accepting cash payments as contributions from fiefdoms as early as 1226 (Segal 2011: 29).

Fiscal affairs, in turn, remained an ongoing concern to the Japanese authorities all through the Middle Ages. This was because the reach of their power into many of the country provinces was highly dependent on local leaders. To fund the governance expenses of these local vassals, central authorities made them manage their fiefdom lands in terms of a tax base. In contrast to medieval England where the lands themselves were the substrate of the geld tax (Barzel and Kiser 2002: 481), it was the landholder who was the direct object of taxation in Japan. This meant that the management of social relations retained more weight in the overall structure of the economy in Japan (compare Fig. 1). This particular Japanese arrangement also caused the emergence of pronounced fiscal problems with the advent and spread of credit. When increasing numbers of vassals came to yield to the temptation to separate consumption from income by offering their lands as collateral for loans, local tax bases shrank with every lot of land seized from defaulting debtors, and so did the effective reach of central powers into the provinces. Central authorities developed a number of counter-strategies including prohibition of mortgages ( $\$ 48$ of the 1232 legal text Goseibai shikimoku), but more especially by way of what may be called 'chronopolicies'. These included (a) the requirement for a 20-year term between acquisition and the recognition of ownership of land (ibid: §8); and (b) recurring decreed reversions of time in the sense of a restitution of earlier ownership 
up to a defined historical point in time, ${ }^{15}$ a policy not known to exist in the European Middle Ages (Ries 2015). Importantly, central authorities' opposition to mortgage credit was motivated by the fiscal needs of their retainers, thus by their own political objectives (restoring the vector of social entitlement). This stands in contrast to the moral constraints in the Western experience, where canonical law channeled money lending into the largely clandestine activity of usury until the end of the medieval period. Japanese authorities were even supportive of consumer (pawn) lending, a stance documented from as early as the first half of the fourteenth century ( $\$ 6$ of the 1336 Kenтu shikimoku). Overall, then, we can see that the Japanese authorities periodically adjusted the time axis backwards for fiscal purposes (through their debt cancellation bills), while they fostered the drafting of future income via the channel of consumer credit. In contrast, no comparable instrumentalisation of time can be observed in medieval economic policy in the West. The objects of economic reasoning, and the evaluation of specific activities, obviously differed between the two societies.

Similarly, with monetisation progressing rapidly in the twelfth and thirteenth centuries, the volume of goods and the extent of their circulation increased rapidly both in Europe (Greif 2006; Pirenne 1925), and in Japan. Notably, late medieval Japan not only featured substantial domestic flows of goods (Fujita 1986), but was also integrated in overseas exchanges, predominantly with China (Tanno 2014) and-for the last half century of that period-with Portuguese traders (Oka 2010). Indications are that authorities in Japan actively supported the construction of larger-less weather-dependent - vessels by levying degressive landing taxes on goods imported into medieval Kobe harbour (Fujita 2004). ${ }^{16}$ In other words, political agents intentionally induced a change in the material configuration of the secondary sector to strengthen private infrastructure.

The secondary sectors of Europe and Japan under conditions of advanced monetisation (vector of economic media) featured similar institutional developments with guild-like craftsmanship associations helping to "secure property rights from the grabbing hand of the state" (Greif 2006). Their origins, though, were somewhat different. While generally guilds in Europe were a city phenomenon, many Japanese $z a$ (lit. 'seats') came into existence when rural craftsmen sought market access through the protection of temples and shrines (Toyoda 1982). Patronage included safe routes to the centres of consumption, and access to outlets within those centres.

Assessing the developments under the vector of economic media against the economic structure in Fig. 1 illustrates, in summary, that trade grew in England and Japan alike. While this might suffice to (directly) explain the growth of the tertiary and (indirectly) of the secondary sector in England, ${ }^{17}$ it cannot possibly do so in the

\footnotetext{
15 Under what was known as tokuseirei medieval Japanese authorities regularly issued orders meant to alleviate economic pressures for indebted individuals. These orders typically specified a date after which any debt incurred was declared cancelled.

16 The harbour was administered by the Tôdaiji temple organization.

17 By 1600, overseas trade effectively enabled England, but not Japan, to substitute secondary activities for primary ones.
} 
case of Japan. This is because the transition toward a monetised economy brought about a much more substantial reduction in economic activities linked to the management of social relations in Japan relative to England.

What was it that over-compensated for the loss of economic activity linked to the management of social relations in the tertiary sector of the Japanese economy? We may pursue two lines of inquiry: the microscopic and the macroscopic. The latter, being more conducive to the aim of our analysis, is the line taken here. The PSF shows us that historic formations of one symbolic form cannot be studied in isolation; we have to account for the entanglements (sometimes conflicted, sometimes mutually enhancing, mostly a mixture of both) between different domains. Exploring the entanglements between the religious and the economic realms (the symbolic form of myth in Cassirer's reading) in the European and Japanese Middle Ages aids our understanding of their differences. To illustrate the power of this analytical approach, we focus on the understanding and handling of time by economic actors, linking it back to our initial observation of differences in sectoral structures.

We posit that the religious realm was decisive in informing the understanding and handling of time in both geographies during the Middle Ages. Contrasting the fundamental stances toward time found in medieval Christianity and Buddhism is admittedly a bold argument, but it will prove instrumental for bringing about a working hypothesis due to further inquiry. The former (broadly: Christianity) relegated the change under the auspices of heavenly foresight by contesting attempts at changing a status quo (Godin 2015). In contrast, Buddhism regarded life as a manifestation of impermanence (skt. anitya, jap. mujō). Salvation was ultimately a matter of self-transformation, even if later schools of thought (such as those dominant in Japan) often allowed for help by intermediary figures. Buddhism also looked favourably upon trade, numbered great merchants among its early supporters, and tolerated money lending (Sharma 1983). The latter is instrumental as it is the pre-condition for separating expenditure from income in the absence of savings.

In the primary sector, we cannot identify material differences. We have already indicated that stockpiling and crop diversification were the dominant attempts to 'linearise time' (in the sense of overcoming seasonality), and both were equally present in the West and in Japan. However, when it comes to innovation as purposeful change, differences begin to emerge. While we have found, in the example mentioned above, a religious authority actively involved in fostering technological advances in civil naval transport in Japan, it has often been said that in late medieval Europe, "innovation and heresy were practically synonyms" (Preus 1972: 2). More recent scholarship supports this view: "innovations unsupported by tradition or Scripture were on the whole seen as corrosive of Christianity" (Illiffe 2000), which meant that "innovation only got de-contested in the last century" (Godin 2015). One of the few exceptions was the wave of innovation in metallurgy and mining brought about by war and the need to finance it (Benoit 1984: 324-325), but it was only from the late fourteenth century when cities slowly became emancipated from the religious sphere, that more significant developments emerged when they started to grant local patents (Long 1991). This was indeed a chronopolitical policy (in the sense of regulating time) as it granted inventors a time-limited monopoly. 
The differences between Japan and England in the handling of time for economic purposes are even more pronounced in economic reasoning. As we have seen, prices remained conspicuously stable in Japan until the very end of its medieval period. In terms of time, price stability is either random (and unlikely to continue for centuries), or it is proof of a deliberate decision not to interfere with the monetary base. An intention of this kind would amount to a measure to moderate the impact of time in a monetising economy.

We can be more confident about the evidence for active handling of time in two other policy areas of medieval Japan: fiscal policy and regulation of financial markets. In fiscal policy, we have already documented regular decrees that set time back to an earlier state with the aim of stabilising fiscal revenues, evidence of a strong link between the economic and political realms. As regards the regulation of financial markets, consumer credit was deliberately fostered in Japan at a time when this kind of capitalising on future income was generally unacceptable to all but ostracised groups in Europe. For Japan, the impact of a religion that took a benevolent view of trade, and accepted change as an essential ingredient of secular life, has thus clearly left its footprint on the economic domain.

In summary, we may tentatively note that the medieval economies of England, continental Europe, and Japan differed most visibly in their approaches to time under the vector of economic media. While our hypothesis pertaining to stockpiling as a way of overcoming seasonality applies equally to both economies, all other instances of reasoning with and controlling of time only apply to Japan. Taking the different sectoral structures of the economies into account (see Fig. 1), we may aggregate the hypotheses pertaining to innovation in trade technology, stability of prices (over time), and the fostering of credit into a tentative partial explanation how the tertiary sector over-compensated the loss of activities linked to 'social entitlement management'. In essence, the particular formation of the economy in the late Japanese medieval period meant that the treatment of time as an economic resource-often identified as a specific trait of modern market economies-was accepted and practiced earlier, and on a broader scale, than in any European economy. The constellation between the locally specific historic formations of the religious, the political, and the economic symbolic forms thus had a decisive influence on differential economic outcomes in the two economies discussed here.

\section{What the theory of symbolic forms can contribute to economics}

\subsection{Theoretical implications}

We have seen that the empirical variety in outcomes observed between the medieval economies of England and Japan is a result of (1) differences in the configurations of rules and their functions, and of (2) the constellations between the symbolic form of the economy and other symbolic forms, specifically that of religion ("myth" in Cassirer's terminology). While the first difference necessitates another form of economic reasoning and activity (namely the brokering and maintenance of social 
entitlements), the second difference guides the choice of patterns of cognition-as documented in our analysis of the handling of time.

Neither symbolic forms, nor their rule-function complexes, can be observed and comprehended as such. They can only be explored by scrutinising their various instantiations in path-dependently evolved configurations and constellations (which one may equally refer to as 'historic formations'). This prerequisite has important theoretical implications for economics. Most importantly, it implies that the economy as a symbolic form is not a time-transcendent integration of ahistoric cognitive models or ideal types. Instead, it is always engendered ex ante in time/space-dependent paradigms and cultural objects. Significantly, this also implies that economic reasoning in the received sense of homo oeconomicus represents but one time- and space-specific actualisation. To render this argument less abstract, we briefly reiterate the definitional elements of a symbolic form:

1. A normative concept orienting the ensemble of rules guiding the operations that produce cultural objects, both physical and intangible.

2. The lifeworld resulting from these recurring operations and their results, including its specific symbols/artefacts.

3. The world of domain-specific imagination/ideas.

4. The set of social practices and associated agent groups.

Interaction between different symbolic forms is present in all of these elements, albeit with varying mutual impact. Examples include the idea of 'white knights' in corporate finance and the link with medieval European mythology, or the interactions between modern mathematics and economics. However, it becomes perhaps most tangible via the fourth element. This is because individual agents may be members of several groups associated with different symbolic forms. For example, an accountant may be involved with a professional organization, and be an active member of their local parish; or, conversely, a medieval Japanese monk could be in charge of the financial operations of his monastery. The set of rules an agent retains and uses for operations will be informed by these associations (Blind and Pyka 2014: 1088-89). For instance, the accountant in our example might, as a result of religious beliefs, apply specific professional standards, such as declining certain types of mandates. On a larger scale, a polity with strong links to a particular religion or ideology might foster or restrict certain activities and ways of economic thinking. Theorizing the economy as a symbolic form requires an understanding of its time- and space-specific configurations, and this includes the constellations relative to other symbolic forms. In short, economic theorizing needs to reflect the plurality of reason as it is engendered in the various symbolic forms and their historic formations.

\subsection{Analytical consequences}

Contemporary philosophical thought in Cassirer's tradition is critical of the empirically led sciences, including much of the discipline of economics: "As reason may 
never be equaled to cause, the routes of substantiation linking cognitive phenomena may never be entirely described in terms of causality" (Kreis 2010: 14). By adding-or rather bringing back-cognition to economics, PSF offers a way of closing this gap. Any analysis of outcomes must, by implication, be based on an inquiry into the particular 'patterns of understanding' involved.

These 'patterns of understanding' refer to cognitive acts in the form of operations guided by a particular normative orientation (noted above as the first definitional element of a symbolic form) arising through condition-action statements which we can conceive as rules. Incidentally, this analytical device is increasingly pertinent in heterodox economic analysis (e.g., empirically in Ostrom 1990, and theoretically in Dopfer and Potts 2008). Put succinctly and more generally: "A rule is defined as the idea that organizes actions and resources into operations" (Dopfer and Potts 2008: 6). When conceiving of 'acts of cognition' as operations (see Blind 2017: 29, 88 ), the concept of rule equally enables the analysis of thought, including, importantly, economic thought (for example, 'When prices rise, think of it as a monetary problem').

Entanglements between social groups and individual agents' cross-associations with groups pertaining to different symbolic forms mean that a reasoned inquiry of relevant rules will frequently involve investigations into matters beyond the core areas of economics. In our case study, we have considered political history and religious studies, but ethnography, technology studies, and even arts and natural sciences may be among the disciplines that need to be drawn upon.

\subsection{Empirical practice}

While an investigation of cause ultimately necessitates an inquiry into the foundations of reason as formed by the individual set of rules an agent retains, there may be several points of departure for studies of the economy as a symbolic form. The choice of analytical pathway will depend on disciplinary preferences, but available routes can be characterised by the involvement of the definitional elements of a symbolic form (Kreis 2010: 449; rephrased above). In concrete terms, abstract top-level concepts (definitional element 3 ) may be gleaned from documents exposing general principles for the sake of guidance or legitimation. We did so in our case study by examination of contemporary legal texts. Next, artefacts (e.g., presents exchanged) documenting the lifeworld related to a symbolic form (element 2) can be accessed for qualitative inquiry, and institutions as social practices (element $4 \mathrm{a}$ ) can be studied in historical or sociological terms. In our case study, we only briefly touched on such practices when discussing the brokering and maintenance of relations in a system of social entitlement. The findings, however, that further study would produce, can then systematically be organized by sector and dominant vector, which finally enables inferences about the specific rules applied (element 1). It is only then, that we can fully understand what one may refer to as the core of received economics: the operations of creating and transmitting artefacts (tangible objects, i.e., of goods and services in a fully monetized economy). 
Similarly, the evolution of the structure of the economy as a symbolic form per se cannot be directly observed, but must be inferred from comparison between historic formations over time. These historical (meta-stable) formations may be analyzed via their sets of governing rules and the ways these are represented and distributed in an agent population (i.e., shares of agents following a specific form of rationality) by way of artefacts, institutions, and established forms of interaction. The empirical methodology for the study of change in rule systems outlined in Blind and Pyka (2014) builds on a population concept to track the structural dynamics, and may be extended to inquire into both configurations within and constellations between symbolic forms.

In a nutshell, the economy as a symbolic form is intelligible through its top-level concept and is directly observable via its lifeworld, artifacts originating from physical operations and social practices. However, inferences are critically required about its constituent rules and its entanglement with other symbolic forms (that are rarely directly observable) to establish the link between reasoning and (economic) operations. Its development over time-which we have sketched in our case study by a rough comparison of three points in time-may more minutely be traced through a population approach that refers to particular agent groups (definitional element 4).

We concede that changes to practices of social scientists "are not following" (Bagg 2017) for the vast majority of social science studies exploring phenomena observed within well-researched and given 'historical formations'. However, we hold that practical consequences are a reality in cases of less well-researched formations (e.g., the study of "15 small-scale societies" discussed in Gintis 2004), or when studying the transformation of 'historical formations' as sketched in our brief case study. In these latter cases, the requirements set out here and in the preceding paragraphs imply a substantial increase in the workload of inquiry into the economy as a symbolic form relative to received approaches. To this is added the particular challenge arising from the limited availability of data suitable for an analysis of reason. This is because the overwhelming share of available data focuses on economic operations and outcomes.

\section{Conclusion}

How can we corroborate our claim that E. Cassirer's philosophy of symbolic forms PSF may contribute to economics inquiries? - in his commentary on Cassirer's PSF Kreis notes: "Philosophical argument remains almost as is even if the empirical base in individual sciences changes substantially" (2010: 12). We hold that this fully applies to PSF when extended into our sketch of the economy as a symbolic form, and as subsequently applied to our case study.

While applicability to an evolving empirical base is indeed the characteristic that one would demand from any theory, received economic theory often fails to pass this test, or passes but with substantial limitations to its epistemological potential. At the heart of this limitation, we identify the "convenient" (Robbins 1932: 98) axiomatisation of one particular configuration of economic reason. Epitomised in received 
homo oeconomicus, even the latest advances into bounded, or limited, rationality cannot fully remedy the theoretical flaws caused by this indulging in convenience.

Building on Cassirer's PSF, we have outlined a corresponding sketch of the economy as a symbolic form. We have then showcased an application to economic outcomes observed in the medieval economies of England and Japan along their development from dominance of the vector of social entitlements to that of economic media (chiefly: money). Contrasting legal with social/political obligations, we were able to formulate a hypothesis for the difference in sectoral structure of these economies: the management and brokerage of social relations may explain the greater share of the tertiary sector in the medieval Japanese economy. Drawing on the entanglement between the symbolic forms of the economy and the religious, we further illustrated how differences in the cognitive apprehension of time between the medieval formations of religion in England and Japan have suggested alternative approaches to its instrumentalisation (i.e., the handling of time) as one of the key parameters of economic operations. In concrete terms, an understanding of time as a variable accessible to policy measures had important impacts on the development of credit markets, fiscal, and innovation policies in Japan. Eventually, most of these developments were only to happen much later in Europe, because instrumentalising time remained 'off limits' for most of the period analyzed here. We trust that our brief case study of how agent reasoning is informed by symbolic forms serves to corroborate the potential epistemological gains of the approach suggested.

Implications of conceiving the economy as a symbolic form include the need to allow for variety in agents' economic reasoning. Arguably, this relinquishing of the conveniently held assumption of universal economic rationality may pose a challenge to economic theorizing concerned with under-researched historical formations, and or with transformation processes-from one to another formation. The entanglement with aspects beyond the disciplinary boundaries of economics further implies that empirical practice in economics at times will need to actively embrace multidisciplinary approaches. While this is likely to cause a substantial increase in workload, we believe that such effort is warranted. This is because we trust that the analytical approach implied by the definitional elements of a symbolic form can be comprehensive, coherent, and stands the test of a changing empirical base. It is comprehensive, because relevant variables are less likely to be missed with the interdisciplinary scope of inquiry via lifeworlds and artefacts. It can be coherent, because it allows establishing intelligible connections between agents, rules, and operations as they bring forth artefacts, concepts, and institutions that constitute specific lifeworlds. And finally, as our comparative analysis of the transition from a dominance of the vector of social entitlements to that of economic media shows, it stands the test of a changing empirical base.

Acknowledgements This research was conducted with support from the European Research Council under the Horizon 2020 Programme (ERC Grant agreement no. 741166). The authors gratefully acknowledge thoughtful comments and criticisms from Jan Steiner, Kurt Dopfer, Alexander Steineck, and Kohei Kataoka, as well as from two anonymous, but dedicated reviewers. On behalf of all authors, the corresponding author states that there is no conflict of interest.

Funding Open access funding provided by University of Zurich. 
Open Access This article is licensed under a Creative Commons Attribution 4.0 International License, which permits use, sharing, adaptation, distribution and reproduction in any medium or format, as long as you give appropriate credit to the original author(s) and the source, provide a link to the Creative Commons licence, and indicate if changes were made. The images or other third party material in this article are included in the article's Creative Commons licence, unless indicated otherwise in a credit line to the material. If material is not included in the article's Creative Commons licence and your intended use is not permitted by statutory regulation or exceeds the permitted use, you will need to obtain permission directly from the copyright holder. To view a copy of this licence, visit http://creativecommons.org/licen ses/by/4.0/.

\section{References}

Adolphson M, Mark Ramseyer J (2009) The competitive enforcement of property rights in medieval Japan: the role of temples and monasteries. J Econ Behav Organ 71(3):660-668

Allen RC (2001) The great divergence in European wages and prices from the middle ages to the first world war. Explor Econ Hist 38:441-447

Aristotle, Forster ESOeconomica. Oxford, Clarendon Press

Barzel Y, Kiser E (2002) Taxation and voting rights in medieval England and France. Ration Soc 14(4):473-507

Bassino JP, Broadberry SN, Fukao K, Gupta B, Takashima M (2015) Japan and the great divergence 725-1874. CEPR Working Paper 10569

Bellah RN (1999) Max Weber and world-denying love: a look a the historical sociology of religion. J Am Acad Relig 67(2):277-330

Benoit P (1984) Technology and crisis: the great depression of the middle ages and the technology of the renaissance. Hist Technol 1(3-4):319-334

Blind G (2017) The entrepreneur in rule-based economics. Springer Nature, Cham

Blind GD, Pyka A (2014) The rule approach in evolutionary economics: a methodological template for empirical research. J Evol Econ 24(5):1085-1105

Broadberry S, Campbell B, Klein A, Overton M, Leeuwen B van (2011) British economic growth, 12701870: an output-based approach. University of Kent School of Economics Working Papers 1203

Broadberry S, Campbell BMS, Klein A, Overton M, van Leeuwen B (2015) British economic growth 1270-1870. Cambridge University Press, Cambridge, UK

Butler B, Purchase S (2004) Personal networking in Russian Post Soviet life. Res Pract Human Resour Manag 12(1):34-60

Cassirer, Ernst. 1923-1929[1953-57]. The Philosophy of Symbolic Forms. New Haven: Yale University Press. 3 volumes.

Cassirer E (1923-1929) Die Philosophie der Symbolischen Formen. Berlin: Bruno Cassirer Verlag. 3 volumes

Cassirer E (1927) Das Symbolproblem und seine Stellung im System der Philosophie. Z Ästhet Allg Kunstwiss 21:295-322

Cassirer E (1979) Symbol, myth, and culture: essays and lectures of Ernst Cassirer, 1935-1945. Yale University Press, New Haven

Cassirer E (1985) Form Und Technik. In: Orth EW, Krois JM, Werle JM (ed) Symbol, Technik, Sprache: Aufsätze Aus Den Jahren 1927-1933, 39-89. Hamburg: Meiner

Cassirer E (1990) Substanzbegriff Und Funktionsbegriff : Untersuchungen Über Die Grundfragen Der Erkenntniskritik. 6. Aufl. Darmstadt: Wissenschaftl. Buchges

Cassirer E (1992) An Essay on Man: An Introduction to the Philosophy of Human Culture. Reprint. New Haven: Yale University Press

Cassirer E (1998) The philosophy of symbolic forms. In: Krois JM, Verene DP. Yale University Press, New Haven, London

Cassirer E (2004) Vom Wesen Und Werden Des Naturrechts. In: Becker R (ed) Aufsätze Und Kleine Schriften (1932-1935). Meiner, Hamburg, pp 203-227

Cassirer E (2005) Axel Hägerström; eine Studie zur schwedischen Philosophie der Gegenwart; Thorilds Stellung in der Geistesgeschichte des achtzehnten Jahrhunderts. In: Rosenkranz C (ed). Vol. Band 21. Gesammelte Werke/Ernst Cassirer. Hamburg: Meiner 
Clark G (2015) Markets and economic growth: the grain market of medieval England. Cliometrica 9(3)

Coyle D (2005) The outlaws of medieval England. Hohunu 3:57-59

Domoto H (2016) 'Kin'yū Ga Kataru Nihonshi - 'Ei'nin No Tokuseirei' Kara Miru Nihonshi [Japanese history as told by Finance: The Ei'nin Debt Cancellation Order].” Tōkyō Jōhō Daigaku Kenkyū Ronsh $\bar{u}$ [Tokyo University of Information Sciences Working Paper Series] 19 (2): 33-36

Dopfer K (2011) Economics in a cultural key: complexity and evolution revisited. In: Davis JB, Hands DW (eds) The Elgar companion to recent economic methodology. Edward Elgar, Cheltenam, UK, pp 319-340

Dopfer K, Potts J (2008) The general theory of economic evolution. Routledge, London

Farris WW (2006) Japan's medieval population: famine, fertility, and warfare in a transformative age. University of Hawai'i Press, Honolulu

Fujita H (1986) Ryūtsū Shisutemu Kara Mita Chūsei Nōson Ni Okeru Ichiba No Kinō [The function of rural markets in medieval Japan from the viewpoint of logistics]. Jinbun Chiri [Human Geogr] 38:316-334

Fujita H (2004) Hyôgo kitaseki nyûsen nôchô ni mieru sekisen o meguru kôsatsu [An examination of the Tax in the record retained at the customhouse of the port of North Hyogo in 1445]. National Museum of Japanese History. Research report Nr. 113, pp. 89-109. Available at: https://www. rekihaku.ac.jp/outline/publication/ronbun/ronbun5/pdf/113005.pdf. Retrieved 9 Sep 2020

Fuller JE, Grandjean BD (2001) Economy and religion in the Neolithic Revolution: material surplus and the proto-religious ethic. Cross Cult Res 35(4):370-399

Gintis H (2004) Towards the unity of the human behavioral sciences. Polit Philos Econ 3(1):37-57

Godin B (2015) Innovation contested. Routledge, New York

Gowdy J, Marshall S (ed) (1998) The original affluent society. In Limited wants, unlimited means: a reader on hunter-gatherer economics and the environment. Island Press

Greif A (2006) Institutions and the path to the modern economy: lessons from medieval trade. Cambridge University Press, New York

Gudeman S (1986) Economics as culture: models and metaphors of livelihood. Routledge, London

Haley JO (2010) Rivers and rice: what lawyers and legal historians should know about medieval Japan. J Jpn Stud 36(2):313-349

Hartman LM (1977) Economics as science and as culture. Am J Agr Econ 59(5):925-930

Heinrichs J (2007) Handlungen: das periodische System der Handlungsarten. Orig.-Ausg., 2., Vollst. überarb. Aufl. Vol. Teil 1. Philosophische Semiotik/Johannes Heinrichs. München: Steno

Hutton G (2016) Inflation and society. Routledge, London

Illiffe R (2000) The masculine birth of time: temporal frameworks of early modern natural philosophy. Br J Hist Sci 33(4):427-453

Katzner DW (2002) What are the questions. J Post Keynes Econ 25(1):51-68

Kauțilya, Meyer JJ (1977) Das altindische Buch vom Welt- und Staatsleben: das Arthaçāstra des Kauţilya. [Nachdruck]. Graz: Akademische Druck- und Verlagsanstalt

Klattenhoff T (2016) Zur Universalität des Tauschmittels. Wie sich Geld als symbolische Form verstehen lässt. In: Endres T, Favuzzi P, Klattenhoff T (eds) Philosophie der Kultur- und Wissensformen - Ernst Cassirer neu lesen. Frankfurt: Peter Lang; pp. 113-136

Klattenhoff T (2018) Geld, eine symbolische form: Perspektiven mit Ernst Cassirer und Georg Simmel. Königshausen\&Neumann, Würzburg

Kreis G (2010) Cassirer Und Die Formen Des Geistes. Berlin: suhrkamp

Ledeneva AC (1998) Russia's economy of favours: blat, networking and informal exchange. Cambridge University Press, Cambridge

Long PO (1991) Invention, authorship, 'intellectual property' and the origin of patents: notes toward a conceptual history. Technol Cult 32:846-884

Luft S (2004) A hermeneutic phenomenology of subjective and objective spirit: Husserl, Natorp, and Cassirer. New Yearb Phenomenol Phenomenol Philos 4:209-248

McCloskey D, Nash J (1984) Corn at interest: the extent and cost of grain storage in medieval England. Am Econ Rev 74:174-187

Miklautz E (2005) Die Produktwelt als symbolische Form. In Alltagsdinge. Erkundungen der materiellen Kultur 1: 43-62. Tübinger Kulturwissenschaftliche Gespräche. Tübingen: Tübinger Vereinigung für Volkskunde

Mueller DC (2004) Models of man: neoclassical, behavioural, and evolutionary. Polit Philos Econ 3(1):59-76 
Naismith R (2014) The social significance of monetization in the early Middle Ages. Past Present 223(1):3-39

Oka M (2010) Shōnin to Senkyōshi - Nanban Bōeki No Sekai [Merchants and missionaries: The world of early foreign trade]. Tokyo University Press, Tōkyō

Ostrom E (1990) Governing the commons. Cambridge University Press, Cambridge

Ostrom E, Basurto X (2011) Crafting analytical tools to study institutional change. J Inst Econ 7(3):317-343

Pirenne H (1925) Medieval cities. Princeton University Press, Princeton

Pomeranz K (2000) The great divergence: China, Europe, and the making of the modern world economy. Princeton University Press, Princeton, N.J

Preus JS (1972) Theological legitimation for innovation in the Middle Ages. Viator 3:1-26

Quinn M (2016) Jeremy Bentham, 'The psychology of economic man', and behavioural economics. Econ Hist Methodol Philos 6(1):3-32

Ries G (2015) Umgehung Und Missbrauch Des Erlasses von Schulden - Ein Diachronischer Vergleich. In Coester-Waltjen D, Lipp V, Waters DWM (eds) Liber Amicorum Makoto Arai. Baden-Baden: Nomos

Robbins L (1932) The nature and significance of economic science. Philos Econ Anthol 1:73-99

Sakurai E (2008) Currency and credit in medieval Japan. Int J Asian Stud 5(1):53-70

Samuel B (2017) When will a Darwinian approach be useful for the study of society. Polit Philos Econ 16(3):259-281

Say J-B (1803) Traité d'économie politique. Deterville, Paris

Segal EI (2011) Coins, trade, and the state: economic growth in early medieval Japan. Vol. 334. Harvard East Asian Monographs. Cambridge: Harvard University Asia Center

Sen A (1981) Ingredients of famine analysis: availability and entitlements. Q J Econ 96(3):433-464

Sharma RS (1983) Material culture and social formations in ancient India. MacMillan, Delhi

Smith A (1776) An Inquiry into the Nature and Causes of the Wealth of Nations. Oxford: Oxford University Press

Stanfield JR (1995) Economics, power, and culture: essays in the development of radical institutionalism. Palgrave Macmillan, New York

Steineck RC (2014) Kritik Der Symbolischen Formen I. Philosophie Interkulturell, Band 3. Stuttgart-Bad Cannstatt: Frommann-Holzboog

Steineck RC (2017) Kritik der symbolischen Formen II: zur Konfiguration altjapanischer Mythologien. Stuttgart: frommann-holzboog

Steineck RC (2020) Kritik der Kultur. Überlegungen zu Cassirers konzept der symbolischen form. Z Kulturphilos 14(1):137-152

Tanno I (2014) Nihon No Ajia Kōeki No Rekishi Josetsu [History of Japan's Trade with Asia]. Kokusai Kei'ei Ronsh $\bar{u}$ [Working Papers in Intl. Business] 48: 1-51

Throsby D (2001) Economics and culture. Cambridge University Press, Cambridge

Totman C (2000) A history of Japan. Blackwell Publishing, Malden, MA

Toyoda T (1982) Za no kenkyū [Researching the guilds]. Vol. 1. of collected works. Tōkyō: Yoshikawa Kōbunkan

Veblen T (1899) The theory of the leisure class: an economic study of institutions. Macmillan, New York von Bertalanffy L (1950) An outline of general system theory. Br J Philos Sci 1(2):134-165

von Glasersfeld E (1989) Facts and the self from a constructivist point of view. Poetics 18(4-5):435-448

Yagi K (1993) Carl Menger's Grundsatze in the Making. Hist Polit Econ 25(4):697-724

Yasuda M (1965) Nihon no hōkenseido no seiritsu ni kan suru kenykūshi [The development of the Japanese insurance system: a research review] Gakushū'in Shigaku [Gakushu'in University History Bulletin] 1: 16-36

Yokoyama K (2011) Kamakura, Muramachi-ki Nihon no Kahei keizai [Japan's monetary economy during the Kamakura and Muromachi Eras]. Oikonomika 47(3/4):25-41

Publisher's Note Springer Nature remains neutral with regard to jurisdictional claims in published maps and institutional affiliations. 